\title{
Formulating Modes of Cooperative Leaning for Education for Sustainable Development
}

\author{
Jordi Colomer ${ }^{1,2, * \mathbb{C}}$, Dolors Cañabate ${ }^{2,3}$, Brigita Stanikūniené ${ }^{4}$ and Remigijus Bubnys ${ }^{4}(\mathbb{C}$ \\ 1 Department of Physics, University of Girona, 17003 Girona, Spain \\ 2 Teaching Innovation Networks on Reflective and Cooperative Learning, Institute of Sciences Education, \\ University of Girona, 17003 Girona, Spain; dolors.canyabate@udg.edu \\ 3 Department of Specific Didactics, University of Girona, 17004 Girona, Spain \\ 4 Panevežys Faculty of Technologies and Business, Technologies and Entrepreneurship Competences Centre, \\ Kaunas University of Technology, 37164 Panevežys, Lithuania; brigita.stanikuniene@ktu.lt (B.S.); \\ remigijus.bubnys@ktu.lt (R.B.) \\ * Correspondence: jordi.colomer@udg.edu; Tel.: +34-630-349-766
}

Citation: Colomer, J.; Cañabate, D.; Stanikūnienė, B.; Bubnys, R. Formulating Modes of Cooperative Leaning for Education for Sustainable Development. Sustainability 2021, 13, 3465. https://doi.org/10.3390/ su13063465

Academic Editor: Marc A. Rosen

Received: 16 March 2021

Accepted: 19 March 2021

Published: 21 March 2021

Publisher's Note: MDPI stays neutral with regard to jurisdictional claims in published maps and institutional affiliations.

Copyright: (c) 2021 by the authors. Licensee MDPI, Basel, Switzerland. This article is an open access article distributed under the terms and conditions of the Creative Commons Attribution (CC BY) license (https:// creativecommons.org/licenses/by/ $4.0 /)$.

\section{Introduction}

In the face of today's global challenges, the practice and theory of contemporary education inevitably focuses on developing the competences that help individuals to find meaningfulness in their societal and professional life, to understand the impact of local actions on global processes and to enable them to solve real-life problems. In this sense, education plays a transformational role, and its content must address relevant social development issues and foster values of cooperation, solidarity, equality, and inclusiveness. Individuals must learn how to cope with unpredictable and unknown future situations [1,2]. Consequently, the traditional ways of acting cannot guarantee that we will choose the correct conduct [3]. In the context of global challenges, we are expected to develop abilities in order to estimate and value risks, danger and uncertainty, to analyze complex systems, to gauge the consequences of actions and to find solutions that promote sustainable changes.

This approach to competence development is consistent with the concept of education for sustainable development (ESD) which UNESCO proposed as a strategy for holistic and transformational education that aims to empower learners to make responsible decisions, taking into account their current and future social, cultural, economic and environmental impacts, and to practice sustainable lifestyles [4]. This has now been recognized as a powerful educational paradigm that penetrates the practice of educational institutions at all levels. Accordingly, researchers are urged to explore and indicate effective pedagogical concepts that will help develop the UN's 17 sustainable development goals (SDGs) [5]. The studies on achieving the learning outcomes of ESD support learner-centered teaching, experiential learning, and interdisciplinary and collaborative decision-making based on inquiry, dialogue, the active exchange of learners' practical experiences and reflection. Experts argue that ESD requires partnership and cooperation with other stakeholders to address the problems of the real world and contribute to sustainable development [6].

Schul [7] and Pavan and Santini [8] reported that learning about sustainability issues and solving real societal challenges are strongly tied to the promise of cooperative learning (CL) and when applying its principles social relationships can be established, along with personal involvement and individual responsibility. CL is a pedagogical practice theoretically supported by the cognitive learning and social interdependence theories and the works of Koffke, Lewin and Deutsch [9]. CL has been studied for the last three decades and evidence of its success in nurturing social interdependence, commitment to the values of fairness, social responsibility, and mutual trust among learners [10-12] has been obtained. Research on CL also emphasizes that CL could be designed to analyze social problems such as those of diversity (racism, sexism, inclusion of people/persons with disabilities), antiso- 
cial behavior, low self-esteem, alienation, and loneliness; and sustainability issues [13-15] such as changes in ecosystems and climate, sustainable consumption, and production, etc.

Studies [16,17] suggest that solving sustainability issues requires the close involvement of the partners concerned. In other words, individuals are more inclined to engage in seeking sustainable solutions and demonstrating the desired behaviors when they are driven by intrinsic motivation. This can be achieved in CL environments [18,19] because two of the CL elements-positive interdependence and individual accountability $[20,21]$ - may increase learner's active engagement. Positive interdependence implies that one cannot succeed unless all one's group members succeed [20], while individual accountability ensures that every learner in a group is accountable for completing the tasks. Working together, group members learn to overcome individual differences, facilitate each other's learning, and nurture personal responsibility, because one's individual input into the teamwork is taken into account. This results in a sense of power to be able make an impact, and fosters an attitude of concern for others and respect for diversity.

Designing educational processes in such a cooperative, learner-centered and actionoriented environment imposes a number of requirements for teachers and educators [22-24], for instance, educators must be equipped with knowledge about real-world case studies, critical incidents, project-based assignments, case studies with local community groups and business and be competent in embedding the deep learning approach [25-27] based on the constructivist view of learning. Deep learning, in contrast to surface learning, is based on empowering students to seek meaning in the material they study, to reflect on previous knowledge and find relationships between the new and existing knowledge structures. Instead of memorizing and reproducing, students interact with others and discuss their understanding, explain their experiences, and jointly construct knowledge. The researchers who advocate for CL $[28,29]$ believe that CL helps to find the interconnectedness between environmental, social, economic, and equity factors, since CL takes in consideration not only interpersonal relationships, but also the connectedness with critical reflection concerning sustainable development and sustainability. The complexity of sustainability challenges requires an interdisciplinary perspective and system thinking since the global problems must be addressed by bringing together the knowledge of different fields such as economics, politics, sociology, science, or engineering [30,31].

Although CL is acknowledged as a relevant educational methodology applied in educational settings, especially in higher education [32,33], broader CL approaches are needed for ESD. The principles of cooperative learning may be helpful to achieve the SDG Partnership for Goals and build long-lasting positive interdependence among other stakeholders - the private sector, industry, NGO organizations, and communities- to then solve the issues of sustainable development. CL for education for sustainable development transcends the boundaries of educational environments and becomes a platform for building collaboration on interdisciplinary projects with different stakeholders [8,34].

Promoting ESD demands an effort to deliver sustainable-oriented competences to all three levels of education [35]. That said, primary and secondary education are still in the process of putting this into practice in teacher and curriculum development so that educational approaches to promoting sustainable development goals can be accomplished [36,37]. ESD pedagogical approaches (especially inter-disciplinary team teaching, building mind and concept maps, project or problem-based learning, community service learning, interlinked teams, and/or place-based environmental education,) demand specific competences such as effective interpersonal relationships and collaboration, interdisciplinary work, and applying systems thinking that all greatly rely on CL [38,39]. The principles behind CL are defined in terms of the ability to (i) work on complex problems in interdisciplinary contexts, (ii) use knowledge and methods from different disciplines, (iii) understand interor multi-disciplinary complex systems across multiple scales, (iv) collaborate to either solve problems or conduct research, and (v) participate in community processes [35]. The latter is seen as a way of understanding cultural perspectives, learning from other perspectives and dealing with varying communicative abilities. All in all, CL is seen as a methodology 
that can, when designed under ESD pedagogical approaches, have a direct impact on sustainable development. Therefore, several modes of CL for ESD are presented in this extensive book, which emphasize the paths, synergies, and feedback that CL provides to afford individuals with opportunities and strategies while encouraging participation and vision.

\section{Conceptual Contributions}

In this special issue, three papers focus on developing conceptual models. In Contribution 2, Torrents, Balagué, Hristovski, Almarcha, and Kelso consider both fostering creativity and cooperation in educational systems as two essential means of nurturing sustainable citizenship. Collaborative creativity can be conceptualized within the framework of coordination dynamics, which is the formation of spontaneous multiscale synergies emerging into complex living systems when interacting with cooperative/competitive environments. The design and co-design of challenging and meaningful CL environments is a key aspect to promoting the spontaneous emergence of multiscale functional synergies and teams. According to the coordination dynamics model, cooperative and competitive processes between systems and their environments are needed to develop collaborative creativity and increase the functional diversity potential of teams. Adequate learning environments, where manipulation of environmental and personal constraints is nested in different levels and time scales, and knowledge of their critical points is seen to develop synergistic creativity.

In Contribution 9, Lenkauskaitè, Colomer, and Bubnys critically analyze the principles of epistemic diversity and democracy and perform an analysis of university students' social construction of knowledge through CL. The authors discuss the possibilities of cooperation in heterogeneous teams: from sharing team experiences to constructing knowledge in groups and highlighting students' critical attitudes towards previous teamwork experiences, which tended to rely more on an individualist rather than social approach to knowledge. When tertiary students were centered on social construction of knowledge, this triggered confusion about roles, dissatisfaction with the unequal contributions other team members made to the group work, and disappointment in the lack of teacher intervention. These findings have established the basis for designing educational approaches for university students to be able to socially construct knowledge through cooperation.

In Contribution 10, Daujotienè, Kazlauskienè, and Bubnys analyze how preconditions, teacher reactions, action strategies, and intervening conditions determine teacher involvement in the organizational modes of teaching. Grounded in the analysis of the research data, developing paths for teacher involvement in the organizational changes manifested itself at both personal and organizational levels. The research revealed that teacher involvement was determined by various preconditions such as, for example, boredom, self-assessment, positive encouragement, support, and/or a negative reaction from others. Each precondition created conditions for manifesting different teacher reactions and action strategies. During teacher instruction, the intervening conditions, i.e., continuous changes, changing of personal attitudes and organizational culture, were revealed. Finally, the contribution elucidates how engaging risk could affect modes of CL.

\section{Contributions on Modes of CL for ESD}

In Contribution 6, Hebles, Yániz-Álvarez-de-Eulate, Alonso-Dos-Santos, and VillardónGallego determine the extent to which faculty training in CL was effectively transferred to university teaching. After specific training in CL in areas as such as Economics, Communication, Mathematics and Knowledge Integration, teachers showed significant improvement in applying social skills, evaluation, reflection, interdependence, and tutoring to their instruction. The authors also found that specific training based on students' needs and context fostered transference to university teaching. Teachers from different disciplines responded differently when applying CL to the classroom after training, especially in evaluation, heterogeneity, and tutoring. The results highlight the importance of a high- 
quality professional development faculty program to foster the dual process of teaching and learning in tertiary education.

In Contribution 8, Ho argue that CL, in which students learn from each other, is useful. The author determines that CL might exert an influence on students' learning outcomes and on the learning objectives provided the educational approach is framed in real-world ESD. A hypothesis model consisting of seven hypotheses was set up, and a questionnaire survey of high school students who participated in the real-world ESD was conducted. Structural equation modeling of data from 2441 respondents supported all seven hypotheses. Implicit learning as a learning process promoted knowledge acquisition as a learning outcome, while explicit learning enhanced self-efficacy. Although knowledge acquisition promoted citizenship development as the learning objective of ESD, self-efficacy did not. Self-efficacy affected knowledge acquisition more than implicit learning.

Contribution 11 by Baena-Morales, Jerez-Mayorga, Fernández-González, and LópezMorales analyzes how the development of the UN Sustainable Development Goals (SDG) was essential for creating values in students. CL was considered a valid technique for developing social relationships and competences to foster SDG 4 (quality education) and SDG 5 (gender equality) in particular. This study describes and characterizes the gender differences between university students in terms of their impressions and behaviors when working cooperatively and engaged in physical education activities. The results are organized into seven dimensions. Female students gave a higher evaluation to relating CL to future teaching roles and to understanding the need for cooperative tasks. Additionally, female students preferred groups to be organized according to academic criteria and that these remain stable throughout the academic period. Both genders valued Aronson's Jigsaw as a good method for developing social competences, although they were more neutral when considering whether it was it effective for improving academic performance. These findings may help to generate a gender-cooperation profile to enable future research modes of peer-to-peer interaction.

In Contribution 12, Bassachs, Cañabate, Serra, and Colomer prove that interdisciplinary educational approaches can foster knowledge and competences for sustainable development in primary education. The intervention methodology employed was an educational and pedagogical approach to teaching science through physical activities and was based on developing dynamic reflective and CL environments to strengthen teaching-learning relationships. Five CL categories: positive interdependence, individual accountability, promotive interaction, the appropriate use of social skills, and group processing, were considered. Within the framework of CL, primary school students reached higher levels of understanding, reflective and critical thinking development. In addition, CL provided students with a greater perception of sustainable development competences through systems and critical thinking, analysis, interpersonal relationships and collaboration, and strategic action.

In Contribution 13, Cañabate, Garcia-Romeu, Menció, Nogué, Planas and Solé-Pla analyze the perception tertiary students (from seven university disciplines) had in terms of motivation, interpersonal relationships, and learning outcomes, during CL activities. The cross-disciplinary dimensional analysis on CL included students' motivation, academic performance, students' relationships within cooperative groups, group organization, and teacher involvement. The subsequent analysis of a sample of 162 student perceptions on the CL dimensions provided evidence not only of positive perceptions in terms of satisfaction, motivation, learning outcomes, and interpersonal relationships, but also that differences in opinion about CL between university degrees were significant, suggesting a strong dependence on the cooperative dimensions on the implemented approach.

In Contribution 17, Mendo Lázaro, León Del Barco, Polo-Del-Río, and RasskinGutman, learn what type of task interdependence is generated in work teams in university contexts and analyze the capacity to discriminate the type of task interdependence of some of the variables that are decisive for a team's success. Their sample consisted of 808 teaching students from six Spanish universities. The authors took self-report measures 
such as task interdependence, attitudes towards teamwork, team potency, and social team skills and the results showed that the students who carried out the tasks in teams with a high level of interdependence are in the minority. However, in saying that, those who worked with high interdependence presented more positive attitudes towards teamwork, greater team potency, and a wider range of social skills in terms of receiving information and self-assertion. Likewise, high interdependence was characterized by high scores in both attitudes and team potency. That said, attitude was the variable that better discriminated the type of task interdependence, allowing for an excellent level of discrimination of high interdependence.

\section{Contribution on Applied Research on CL}

In Contribution 1, de Sousa establishes that when including a participatory approach in teaching and learning in education for sustainable development, the social learning indicators: learning, critical thinking, problem solving and dealing with conflict, emerged. Under this instructional approach, students might use their personal perspectives when participating collaboratively to work towards resolving environmental issues. In addition, the author proves that social learning indicators might emerge when a participatory approach is implemented.

In Contribution 3, Muñoz-Martínez, Gárate-Vergara, and Marambio-Carrasco propose cooperative teaching instruction, based on both methodological and organizational transformations, to respond to student diversity. The observed transformation emerged when implementing actions in the classroom associated to the CL methodology. The results of these actions were validated over four years of CL implementation and showed that the transformation and improvement in teaching practices based on CL increased student inclusivity. Among the central conclusions was evidence that internal improvement in organizational management and inclusive teaching practices could be dimensionalized in terms of involvement, support, and continuous development of teachers in quality educational instruction.

In Contribution 4, González-Valero, Vidal-Conti, Zurita-Ortega, and Palou-Sampol observe individuals with intellectual disabilities who were not engaging in enough physical activity to acquire health benefits. Once CL was applied, however, it proved to be an effective tool for inclusion and for improving healthy physical habits. The authors' explanatory model incorporated considerations on quality of life, active time in cooperative activities, body mass index and age, as well as the relationship between individuals' sex and their intellectual disabilities. Age was directly associated with body mass index in both sexes. Likewise, age was positively related to the active time of women. Quality of life was directly associated with active time, and body mass index was inversely related to active time. This study shows the importance of active time during work and CL for individuals with intellectual disabilities, as this is associated with an improvement in quality of life and a reduction in the problems caused by a sedentary lifestyle and/or being overweight or obese.

In Contribution 5, Wang, and Guo explore a student-oriented curriculum model on Renewable Energy Sources (RES), (because RES might result in being a solution to the energy problem), in a Chinese university where training in relevant skills and qualities became a key part of the instruction strategy. Based on the Taylor Principle and PDCA Cycle Theory (Plan, Do, Check, Act), the authors proposed a "Student-centered inquiry" RES course model together with three reference templates for the design, teaching, and evaluation processes of the course. Results indicate that: (a) there was a relationship between the new curriculum model and the students' academic performance, (b) the improvement in low-achieving students was more significant than in high-achieving students and (c) the new curriculum model might have positive effects on students in terms of knowledge transfer, methodology, reductionism, and consciousness formation.

In Contribution 7, the review by Legrain, Becerra-Labrador, Lafont, and Escalié argue that the pre-service teachers (PST) socialization depended on various actors. On the one 
hand, researchers might help PST to build knowledge about variables that impact teaching models, including CL. Whereas, on the other hand, in-service schoolteachers help PST to efficiently implement teaching-learning environments, including CL configurations in real classrooms. The authors examined the conditions in which synergy between research and professional training could be strengthened to prepare PST in physical education to establish CL permanently in school curricula. The authors also proposed PST be involved in their project in opening up new avenues in four main perspectives of CL. Furthermore, the authors suggest PST be trained in CL designs by experiencing the instructional approaches and developing competencies to cope with constraints around information sharing, to professionally socialize them through applying the relevant connections between research and applied practice, and to continually assess what a realistic and sustainable vision of CL can be.

In Contribution 14, Krstić, Filipe, and Chavaglia examine the interdependence between higher education on one hand and the competitiveness of the economy and sustainable development on the other. To examine this interdependence, they used a sample that included EU member states and candidate countries. Their research findings indicate a strong correlation between higher education and the competitiveness of the economy and sustainable development. These results may serve as a "global benchmark" for future public policy in higher education.

In Contribution 15, Asif, Guangming, Haider, Colomer, Kayani, and Amin show that sustainable development is promoted when the system of education provides the learners with an opportunity to equip themselves with moral values, skills, and competences that assist them in effecting positive personal and community changes. Teachers play an important role as moral agents, and students consider the teacher to be a role model. Therefore, the understanding and beliefs of teachers, in terms of moral education, play a pivotal role in mentoring the personality of the learners. This particular comparative study aimed to assess university teachers' practices and beliefs (in terms of moral education) in China and Pakistan and constructed seven themes with which to categorize these. For the quantitative analysis, 300 teachers' responses were collected using a validated questionnaire. The results showed that the majority of Pakistani teachers possess a conservative mindset. According to the Pakistani teachers' perspective, sovereignty of divine laws, loyalty to the constitution of the state, and a sense of serving society were the ultimate aims of moral education. Chinese teachers, on the other hand, were promoting a political ideology that stressed collectivism in a socialist approach, with family and social values being most relevant. In the light of the dearth of literature, this study has implications for future research in the fields of English as a Foreign Language (EFL) and Islamic Studies in higher education, as it is a longitudinal study that provided insight into how teachers' beliefs and attitudes are shaped over time and from moral educational experiences.

In Contribution 16, Zhang, Zhu, Mu, Zhang, and Cui determine that sharing educational resources (ERs) among campuses could avoid wasting or repeatedly constructing ERs and benefits sustainable utilization of resources. For hardware educational resources (HERs) significantly attached to land resources, whether these have surplus shareable potential was found to be the key factor relating to inter-campus sharing. If all eleven campuses could freely share HERs, there would be an overall surplus of the five kinds of HER (i.e., classroom, laboratory, library, indoor sports room, and canteen). The comprehensive management framework included sustainable concepts such as guidance, cooperation system construction, planning control, benefit adjustment and technological innovation.

\section{Discussion and Perspectives}

Some of the educational proposals that are published in this special issue have focused on reformulating educational instruction through CL. Continuous contingent interaction between actors in education demands new analysis and perspectives on how CL can be best operationalized to maximize students' acquisition of individual, group and social competences. Some of the reformulations, especially in tertiary education, should, for 
example, consider the perspective of management research in which cooperation demands a methodological framework for collaboration at all levels of education and for collaborative management research between academics and private sector [38,39].

Several authors have introduced reflective teaching and learning processes using reflective methodologies during group processing to gain information on the acquisition of learning outcomes, especially through critical reflection on CL dimensions [40]. The emphasis has been on developing students' critical thinking, strategic action, and interpersonal relationships through a set of structured, teacher-led practices that have verified the need to better link education approaches to student learning process through reflection, mainly during CL group processing. The support of the teacher is essential in promoting, for example, the development and knowledge of professional identity, in which CL fosters higher levels of student self-regulation, commitment, perception of peers' promotive tasks, and task motivation through peer-to-peer cooperation. Cooperative instruction has also been reported to mediate students' self-reported cognitive activation, and the degree of students' intrinsic motivation [41].

When implementing $C L$, some authors have individual shared responsibilities with feedback on the teaching and learning process between teacher and student interactions, which itself is a major issue still to be fully developed. Teachers are responsible for designing opportunities for students to act in response to feedback information, while students have the responsibility to participate and use both peer-to-peer and teacher-student feedback. A structured feedback process for both students and teachers would enable and facilitate students' development in knowledge and/or competence acquisition, development of interpersonal relationships and higher orders of CL. When teachers foster a continuous dialogic feedback process at the cognitive, motor, and affective levels, students' interpersonal skills in negotiation and sense of autonomy improved. This systematic work on feedback provides group processing with relevant information in order to improve the process and produce meaningful learning outcomes, thus facilitating self-regulatory learning and provoking a cognitive challenge. Highly-structured CL promotes motivation, content knowledge and responsibility, as well as the five elements that mediate CL effectiveness: positive interdependence, individual accountability, promotive interaction, group processing, and social skills [42]. That said, research must now focus on determining which feedback elements guarantee the development of positive interdependence and promote interdependence in order to also improve interpersonal skills, individual responsibility and group processing.

The contributions to this special issue all indicate the need for teachers/educators to be trained in how to reorient the curricula skills so students can practice the principles of sustainability. And the important issue here is developing teachers' understanding of sustainability itself and empowering them to experience the benefits of applying CL methodologies based on ESD principles. CL can be understood as an instructional approach that assists students in developing their awareness of others, increases their emotional intelligence, enhances attitudes towards racial minorities and disabilities, engenders sensitivity to gender issues, and is rooted in a sense of reformulating peer-to-peer student interactions and peer-to-teacher interactions as well [10,14,15].

However, if we intend to make sustainable behavior a habitual practice or even a lifestyle approach, simply reinforcing the appropriate behavior of students during CL in the classroom environment is not enough. Laurie et al. [43] and Mulà et al. [44] consider the idea of developing relevant institutional policies or management structures to support ESD in the curriculum or sustain teachers' critical reflection on ESD in their practice and even their motivation to develop and apply educational innovations [45]. In terms of sustaining the practice of CL for ESD at the institutional level, emphasis must be placed on the culture of the organizational perspectives. The relevant questions for research to consider might include what organizational culture would support the principles of CL for EDS. Likewise, in what ways organizational culture frames the implementation of CL across a variety of 
content areas. And finally, what organizational culture elements are essential for fostering cooperative relationships with other stakeholders in the pursuit of quality in ESD.

\section{List of Contributions}

1. de Sousa, L.O. Learning Experiences of a Participatory Approach to Educating for Sustainable Development in a South African Higher Education Institution Yielding Social Learning Indicators. Sustainability 2021, 13, 3210. https: / / doi.org/10.3390/su13063210.

2. Torrents, C.; Balagué, N.; Hristovski, R.; Almarcha, M.; Kelso, J.A.S. Metastable Coordination Dynamics of Collaborative Creativity in Educational Settings. Sustainability 2021, 13, 2696. https: / / doi.org/10.3390/su13052696.

3. Muñoz-Martínez, Y.; Gárate-Vergara, F.; Marambio-Carrasco, C. Training and Support for Inclusive Practices: Transformation from Cooperation in Teaching and Learning. Sustainability 2021, 13, 2583. https: / / doi.org/10.3390/su13052583.

4. González-Valero, G.; Vidal-Conti, J.; Zurita-Ortega, F.; Palou-Sampol, P. Active Time in Cooperative Activities, Quality of Life and Body Mass Index in Individuals with Intellectual Disabilities. A Model of Structural Equations. Sustainability 2021, 13, 2341. https:/ / doi.org/10.3390/su13042341.

5. Wang, X.; Guo, L. How to Promote University Students to Innovative Use Renewable Energy? An Inquiry-Based Learning Course Model. Sustainability 2021, 13, 1418.

6. Hebles, M.; Yániz-Álvarez-de-Eulate, C.; Alonso-Dos-Santos, M.; Villardón-Gallego, L. Towards a Cooperative Learning Environment in Universities through In-Service Training. Sustainability 2021, 13, 1112.

7. Legrain, P.; Becerra-Labrador, T.; Lafont, L.; Escalié, G. Designing and Implementing a Sustainable Cooperative Learning in Physical Education: A Pre-Service Teachers' Socialization Issue. Sustainability 2021, 13, 657.

8. Ho, B.Q. Effects of Learning Process and Self-Efficacy in Real-World Education for Sustainable Development. Sustainability 2021, 13, 403.

9. Lenkauskaite, J.; Colomer, J.; Bubnys, R. Students' Social Construction of Knowledge through Cooperative Learning. Sustainability 2020, 12, 9606.

10. Daujotienè, L.; Kazlauskienè, A.; Bubnys, R. Teacher Involvement in Organisational Change: From Engaging Risk to Cooperative Learning. Sustainability 2020, 12, 9447.

11. Baena-Morales, S.; Jerez-Mayorga, D.; Fernández-González, F.T.; López-Morales, J. The Use of a Cooperative-Learning Activity with University Students: A Gender Experience. Sustainability 2020, 12, 9292.

12. Bassachs, M.; Cañabate, D.; Serra, T.; Colomer, J. Interdisciplinary Cooperative Educational Approaches to Foster Knowledge and Competences for Sustainable Development. Sustainability 2020, 12, 8624.

13. Cañabate, D.; Garcia-Romeu, M.L.; Menció, A.; Nogué, L.; Planas, M.; SoléPla, J. Cross-Disciplinary Analysis of Cooperative Learning Dimensions Based on Higher Education Students' Perceptions. Sustainability 2020, 12, 8156.

14. Krstić, M.; Filipe, J.A.; Chavaglia, J. Higher Education as a Determinant of the Competitiveness and Sustainable Development of an Economy. Sustainability 2020, 12, 6607.

15. Asif, T.; Guangming, O.; Haider, M.A.; Colomer, J.; Kayani, S.; Amin, N. Moral Education for Sustainable Development: Comparison of University Teachers' Perceptions in China and Pakistan. Sustainability 2020, 12, 3014.

16. Zhang, Y.; Zhu, H.; Mu, B.; Zhang, X.; Cui, X. Inter-Campus Sharable Potential of Hardware Educational Resources in A University Town: Connotation, Determination Method and A Case Study. Sustainability 2020, 12, 1636.

17. Mendo Lázaro, S.; León Del Barco, B.; Polo-Del-Río, M.-I.; Rasskin-Gutman, I. Predictive Factors of Task Interdependence in the University Context. Sustainability 2020, 12, 100. 
Author Contributions: Conceptualization, J.C.; methodology, all; validation, all.; formal analysis, R.B.; investigation, all; resources, all; data curation, all; writing-original draft preparation, J.C., R.B., B.S; writing - review and editing, J.C., R.B., B.S.; supervision, D.C. and J.C.; project administration, J.C; funding acquisition, all. All authors have read and agreed to the published version of the manuscript.

Funding: This research was funded by the Institute of Sciences Education of the University of Girona, grant number XIDAR/01-2021.

Data Availability Statement: Not applicable.

Conflicts of Interest: The authors declare no conflict of interest.

\section{References}

1. Longworth, N. Learning Cities, Learning Regions, Learning Communities: Lifelong Learning and Local Government, 1st ed.; Routledge: New York, NY, USA; Taylor \& Francis Group: Abingdon, ON, Canada, 2006.

2. Jarvis, P. Adult Education and Lifelong Learning: Theory and Practice, 4th ed.; Routledge: New York, NY, USA; Taylor \& Francis Group: Abingdon, ON, Canada, 2010.

3. Adomßent, M.; Hoffmann, T. The Concept of Competencies in the Context of Education for Sustainable Development (ESD). 2013. Available online: http://www.esd-expert.net/assets/130314-Concept-Paper-ESD-Competencies.pdf (accessed on 21 December 2020).

4. UNECE. Strategy for Education for Sustainable Development. 2005. Available online: https://unece.org/DAM/env/documents/ 2005/cep/ac.13/cep.ac.13.2005.3.rev.1.e.pdf (accessed on 16 December 2020).

5. UNESCO. Education for Sustainable Development Goals: Learning Objectives. 2017. Available online: https://unesdoc.unesco. org/ark:/48223/pf0000247444?utm_sq=gj34xbfn94 (accessed on 21 December 2020).

6. Yarime, M.; Trencher, G.; Mino, T.; Scholz, R.W.; Olsson, L.; Ness, B.; Frantzeskaki, N.; Rotmans, J. Establishing Sustainability Science in Higher Education Institutions: Towards an Integration of Academic Development, Institutionalization and Stakeholder Collaborations. Sustain. Sci. 2012, 7, 101-113. [CrossRef]

7. Schul, J.E. Revisiting an Old Friend: The Practice and Promise of Cooperative Learning for the Twenty-First Century. Soc. Stud. 2011, 102, 88-93. [CrossRef]

8. Pavan, D.; Santini, F. Italy Co-operative Learning and Education for Sustainable Development. J. Coop. Stud. 2013, 46, 57-61.

9. Johnson, D.W.; Johnson, R.T.; Smith, K.A. Cooperative Learning Returns to College what Evidence is There That it Works? Chang. Mag. High. Learn. 1998, 30, 26-35. [CrossRef]

10. Johnson, D.W.; Johnson, R.T. An Educational Psychology Success Story: Social Interdependence Theory and Cooperative Learning. Educ. Res. 2009, 38, 365-379. [CrossRef]

11. Slavin, R.E. Research on Cooperative Learning and Achievement: What We Know, What We Need to Know. Contemp. Educ. Psychol. 1996, 21, 43-69. [CrossRef]

12. Roseth, C.J.; Johnson, D.W.; Johnson, R.T. Promoting Early Adolescents' Achievement and Peer Relationships: The Effects of Cooperative, Competitive, and Individualistic Goal Structures. Psychol. Bull. 2008, 134, 223-246. [CrossRef] [PubMed]

13. Johnson, D.W.; Johnson, R.T. Cooperative learning, values, and culturally plural classrooms. In Classroom Issues: Practice, Pedagogy and Curriculum, 1st Ed.; Leicester, M., Modgil, S., Modgil, S., Eds.; Routledge: London, UK, 1999; pp. $29-47$.

14. Cabrera, A.F.; Crissman, J.L.; Bernal, E.M.; Nora, A.; Terenzini, P.T.; Pascarella, E.T. Collaborative Learning: Its Impact on College Students' Development and Diversity. J. Coll. Stud. Dev. 2002, 43, 20-34.

15. Van Ryzin, M.J.; Roseth, C.J. Cooperative Learning in Middle School: A Means to Improve Peer Relations and Reduce Victimization, Bullying, and Related Outcomes. J. Educ. Psychol. 2018, 110, 1192-1201. [CrossRef]

16. Grønhøj, A.; Thøgersen, J. Why Young People Do Things for the Environment: The Role of Parenting for Adolescents' Motivation to Engage in Pro-Environmental Behaviour. J. Environ. Psychol. 2017, 54, 11-19. [CrossRef]

17. De Groot, J.I.; Steg, L. Relationships Between Value Orientations, Self-Determined Motivational Types and Pro-Environmental Behavioural Intentions. J. Environ. Psychol. 2010, 30, 368-378. [CrossRef]

18. Warburton, K. Deep Learning and Education for Sustainability. Int. J. Sustain. High. Educ. 2003, 4, 44-56. [CrossRef]

19. Fernández-Espínola, C.; Abad Robles, M.T.; Collado-Mateo, D.; Almagro, B.J.; Castillo Viera, E.; Giménez Fuentes-Guerra, F.J. Effects of Cooperative-Learning Interventions on Physical Education Students' Intrinsic Motivation: A Systematic Review and Meta-Analysis. Int. J. Environ. Res. Public Health 2020, 17, 4451. [CrossRef]

20. Johnson, D.W.; Johnson, R.T. Making Cooperative Learning Work. Theory Prac. 1999, 38, 67-73. [CrossRef]

21. Slavin, R.E. Comprehensive Approaches to Cooperative Learning. Theory Prac. 1999, 38, 74-79. [CrossRef]

22. UNECE (United Nations Economic Commission for Europe). Learning for the Future. Competences in ESD for Educators. 2012. Available online: http://www.unece.org/fileadmin/DAM/env/esd/ESD_Publications/Competences_Publication.pdf (accessed on 16 December 2020).

23. Barth, M.; Rieckmann, M. Academic Staff Development as a Catalyst for Curriculum Change towards Education for Sustainable Development: An Output Perspective. J. Clean. Prod. 2012, 26, 28-36. [CrossRef] 
24. Rieckmann, M. Future-Oriented Higher Education: Which Key Competencies Should Be Fostered through University Teaching and Learning? Futures 2012, 44, 127-135. [CrossRef]

25. Ramsden, P. Learning to Teach in Higher Education, 2nd ed.; Routledge: London, UK; Taylor \& Francis Group: New York, NY, USA, 2003.

26. Biggs, J.B. Teaching for Quality Learning at University: What the Student Does, 4th ed.; McGraw-Hill Education: London, UK, 2011.

27. Trigwell, K.; Prosser, M.; Waterhouse, F. Relations Between Teachers' Approaches to Teaching and Students' Approaches to Learning. High Educ. 1999, 37, 57-70. [CrossRef]

28. O'Brien, W.; Sarkis, J. The Potential of Community-Based Sustainability Projects for Deep Learning Initiatives. J. Clean. Prod. 2014, 62, 48-61. [CrossRef]

29. Bassachs, M.; Cañabate, D.; Nogué, L.; Serra, T.; Bubnys, R.; Colomer, J. Fostering Critical Reflection in Primary Education through STEAM Approaches. Educ. Sci. 2020, 10, 384. [CrossRef]

30. Walshe, N. An Interdisciplinary Approach to Environmental and Sustainability Education: Developing Geography Students' Understandings of Sustainable Development Using Poetry. Environ. Educ. Res. 2017, 23, 1130-1149. [CrossRef]

31. Annan-Diab, F.; Molinari, C. Interdisciplinarity: Practical approach to advancing education for sustainability and for the Sustainable Development Goals. Int. J. Manag. Educ. 2017, 15, 73-83. [CrossRef]

32. Felder, R.M.; Brent, R. Effective Strategies for Cooperative Learning. J. Coop. Collab. Coll. Teach. 2001, 10, 69-75.

33. Millis, B.J. Cooperative Learning in Higher Education: Across the Disciplines, Across the Academy, 1st ed.; Stylus Publishing: Sterling, VA, USA, 2010.

34. Bouwen, R.; Taillieu, T. Multi-party Collaboration as Social Learning for Interdependence: Developing Relational Knowing for Sustainable Natural Resource Management. J. Community Appl. Soc. 2004, 14, 137-153. [CrossRef]

35. Lozano, R.; Merrill, M.Y.; Sammalisto, K.; Ceulemans, K.; Lozano, F.J. Connecting Competences and Pedagogical Approaches for Sustainable Development in Higher Education: A Literature Review and Framework Proposal. Sustainability 2017, 9, 1889. [CrossRef]

36. Sachs, J.D.; Schmidt-Traub, G.; Mazzucato, M.; Messner, D.; Nakicenovic, N.; Rockström, J. Six transformationsto achieve the sustainable development goals. Nat. Sustain. 2019, 2, 805-814. [CrossRef]

37. Tejedor, G.; Segalàs, J.; Barrón, A.; Fernández-Morilla, M.; Fuertes, M.T.; Ruiz-Morales, J.; Gutiérrez, I.; García-González, E.; Aramburuzabala, P.; Hernández, À. Didactic strategies to promote competencies in sustainability. Sustainability 2019, 11, 2086. [CrossRef]

38. Bassachs, M.; Cañabate, D.; Serra, T.; Colomer, J. Interdisciplinary Cooperative Educational Approaches to Foster Knowledge and Competences for Sustainable Development. Sustainability 2020, 12, 8624. [CrossRef]

39. Berger, C.; Möslein, K.; Oiller, F.; Reichwald, R. Co-designing modes of cooperation at the customer interface: Learning from exploratory research. Eur. Manag. Rev. 2005, 2, 70-87. [CrossRef]

40. Colomer, J.; Serra, L.; Cañabate, D.; Serra, T. Evaluating Knowledge and Assessment-Centered Reflective-Based Learning Approaches. Sustainability 2018, 10, 3122. [CrossRef]

41. Hänze, M.; Berger, R. Cooperative learning, motivational effects, and student characteristics: An experimental study comparing cooperative learning and direct instruction in 12th grade physics classes. Learn. Instr. 2007, 17, 29-41. [CrossRef]

42. Cecchini, J.A.; Fernandez-Rio, J.; Mendez-Gimenez, A.; Gonzalez, C.; Sanchez-Martínez, B.; Carriedo, A. High versus lowstructured cooperative learning. Effects on prospective teachers' regulation dominance, motivation, content knowledge and responsibility. Eur. J. Teach. Educ. 2020, 1-16. [CrossRef]

43. Laurie, R.; Nonoyama-Tarumi, Y.; Mckeown, R.; Hopkins, C. Contributions of education for sustainable development (ESD) to quality education: A synthesis of research. J. Educ. Sust. Dev. 2016, 10, 226-242. [CrossRef]

44. Mulà, I.; Tilbury, D.; Ryan, A.; Mader, M.; Mader, M.; Dlouhá, J.; Mader, C.; Benayas, J.; Dlouhý, J.; Alba, D. Catalysing change in higher education for sustainable development. Int. J. Sustain. High. Educ. 2017, 18. [CrossRef]

45. Ayllón, S.; Alsina, Á.; Colomer, J. Teachers' involvement and students' self-efficacy: Keys to achievement in higher education. PLoS ONE 2019, 14, e0216865. [CrossRef] 